\title{
Rubidium-Carbonate-Doped 4,7-Diphenyl-1,10-phenanthroline Electron Transporting Layer for High-Efficiency p-i-n Organic Light Emitting Diodes
}

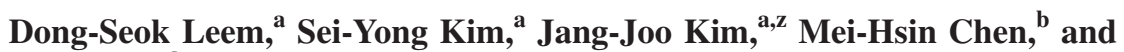 \\ Chih-I Wu ${ }^{\text {b }}$ \\ ${ }^{a}$ Department of Materials Science and Engineering and Center for Organic Light Emitting Diode, \\ Seoul National University, Seoul 151-744, Korea \\ ${ }^{b}$ Department of Electrical Engineering and Graduate Institute of Electro-Optical Engineering, \\ National Taiwan University, Taipei 10617, Taiwan
}

\begin{abstract}
We investigated the electrical properties and charge transport mechanisms of a rubidium-carbonate $\left(\mathrm{Rb}_{2} \mathrm{CO}_{3}\right)$-doped 4,7 -diphenyl1,10-phenanthroline (Bphen) electron transporting layer (ETL). The electron-only devices and photoemission spectroscopy analysis revealed that the formation of doping-induced gap states dominantly contributes to the improvement of carrier transport characteristics of the doped system. High-efficiency green phosphorescent p-doping/intrinsic/n-doping (p-i-n) organic light emitting diodes were demonstrated using the $\mathrm{Rb}_{2} \mathrm{CO}_{3}$-doped Bphen ETL and rhenium oxide (ReO ${ }_{3}$-doped $N, N^{\prime}$-diphenyl- $N, N^{\prime}$-bis $\left(1,1^{\prime}\right.$-biphenyl)-4, $4^{\prime}$-diamine hole transporting layer, exhibiting an external quantum efficiency of $19.2 \%$, power efficiency of $76 \mathrm{~lm} / \mathrm{W}$, and low operation voltage of $3.6 \mathrm{~V}$ at $1000 \mathrm{~cd} / \mathrm{m}^{2}$.

(C) 2008 The Electrochemical Society. [DOI: 10.1149/1.3007239] All rights reserved.
\end{abstract}

Manuscript submitted August 26, 2008; revised manuscript received October 6, 2008. Published October 27, 2008.

Organic light emitting diodes (OLEDs) have been recognized and partially realized as next-generation flat-panel displays and solid-state lighting. ${ }^{1,2}$ Highly efficient OLEDs with external quantum efficiency (EQE) over 20\% have been demonstrated through the development of materials and device structures. ${ }^{2-4}$ However, a relatively high driving voltage causes loss of power efficiency. To overcome the limitations, a doping concept has been applied to the conventional OLED structure and created promising p-doping/intrinsic/ $\mathrm{n}$-doping ( $\mathrm{p}-\mathrm{i}-\mathrm{n})$ OLEDs exhibiting low operation voltage, high efficiency, and long lifetime. ${ }^{5-8}$

The doping technology of charge-transporting layers is a key issue in fabricating high-performance p-i-n OLEDs with low power consumption. Various p-dopants for a hole transporting layer (HTL) have been developed, which include an organic-based dopant of $\mathrm{F}_{4}$-TCNQ, ${ }^{5-8}$ metal halides such as $\mathrm{FeCl}_{3}$ and $\mathrm{SbCl}_{5},{ }^{9,10}$ and metal oxides like $\mathrm{WO}_{3}$ and $\mathrm{MoO}_{3}{ }^{11,12}$ Recently, our group has also developed another metal-oxide p-doping system based on rhenium oxide $\left(\mathrm{ReO}_{3}\right)$, showing an efficient p-doping property coming from the formation of charge-transfer complex within the HTL. ${ }^{13}$ Furthermore, the developed p-doping system facilitates easy codeposition with organic molecules by a conventional thermal evaporator due to low-temperature deposition $\left(\sim 350^{\circ} \mathrm{C}\right)$ of $\mathrm{ReO}_{3}$. In contrast, there are fewer material systems reported to date for $\mathrm{n}$-doping of an electron transporting layer (ETL). Alkali metals such as $\mathrm{Li}$ and $\mathrm{Cs}^{5-7}$ or alkali metal carbonate like $\mathrm{Cs}_{2} \mathrm{CO}_{3}{ }^{14,15}$ have been applied as n-dopants. However, limited work ${ }^{14-16}$ has been carried out for the application of a metal carbonate-based n-doping system, requiring further research and development on the efficient n-doping system.

In this work, we report on the electrical properties and possible charge-transport mechanisms of a newly developed rubidium carbonate $\left(\mathrm{Rb}_{2} \mathrm{CO}_{3}\right)$-doped ETL system by means of a single carrier device test and photoemission spectroscopy analysis. Highefficiency p-i-n OLEDs are also fabricated using the developed n-doping system.

Indium tin oxide (ITO)-coated glass substrates (150 nm thick) were prepared and cleaned. ${ }^{13}$ Electron-only devices with ITO/4,7diphenyl-1,10-phenanthroline (Bphen)/Bphen:8-25 wt \% $\mathrm{Rb}_{2} \mathrm{CO}_{3} /$ $\mathrm{Al}$ structure were fabricated and characterized to determine the suitable doping concentration in the Bphen layer. After optimization of $\mathrm{n}$-doping condition, the organic structures for $\mathrm{p}$-i-n OLEDs with $2-8$ wt $\% \quad \mathrm{ReO}_{3}$ doped $N, N^{\prime}$-diphenyl- $N, N^{\prime}$-bis $\left(1,1^{\prime}\right.$-biphenyl)-

${ }^{\mathrm{z}}$ E-mail: jjkim@snu.ac.kr
4, $4^{\prime}$-diamine (NPB), undoped NPB, 8 wt $\% \quad \operatorname{Ir}(\text { ppy })_{3}$-doped 4-4' $-N, N^{\prime}$-dicarbazolylbiphenyl, 8 wt \% $\operatorname{Ir}(\text { ppy })_{3}$-doped Bphen, undoped Bphen, and 15 wt $\% \mathrm{Rb}_{2} \mathrm{CO}_{3}$-doped Bphen were successively deposited as p-HTL, HTL, a double emission layer, ETL, and n-ETL, respectively. The ultraviolet photoemission spectroscopy (UPS) analysis of n-ETL was also carried out with $\mathrm{He}$ (II) excitation light $(40.8 \mathrm{eV})$. The current density-voltage-luminance $(J-V-L)$ characteristics of the devices were measured by a Keithley 2400 semiconductor parameter analyzer and Photo Research PR-650 spectrophotometer. All the devices were encapsulated prior to the measurement.

Figure 1 shows the $J-V$ characteristics of the electron-only devices consisting of ITO/Bphen $(20 \mathrm{~nm}) / \mathrm{Bphen}: 8-25 \mathrm{wt} \% \mathrm{Rb}_{2} \mathrm{CO}_{3}$ $(30 \mathrm{~nm}) / \mathrm{Al}$ structures. For comparison, the $J-V$ curve of the ITO/ undoped $\mathrm{Bphen} / \mathrm{LiF} / \mathrm{Al}$ is also included in Fig. 1. The devices with the doped layer exhibit higher current density than the undoped device, confirming the effectiveness of $\mathrm{Rb}_{2} \mathrm{CO}_{3}$ doping in ETL. Specifically, the device with a Bphen/Bphen: $15 \% \mathrm{Rb}_{2} \mathrm{CO}_{3}$ layer exhibits a relatively low threshold voltage as well as high current

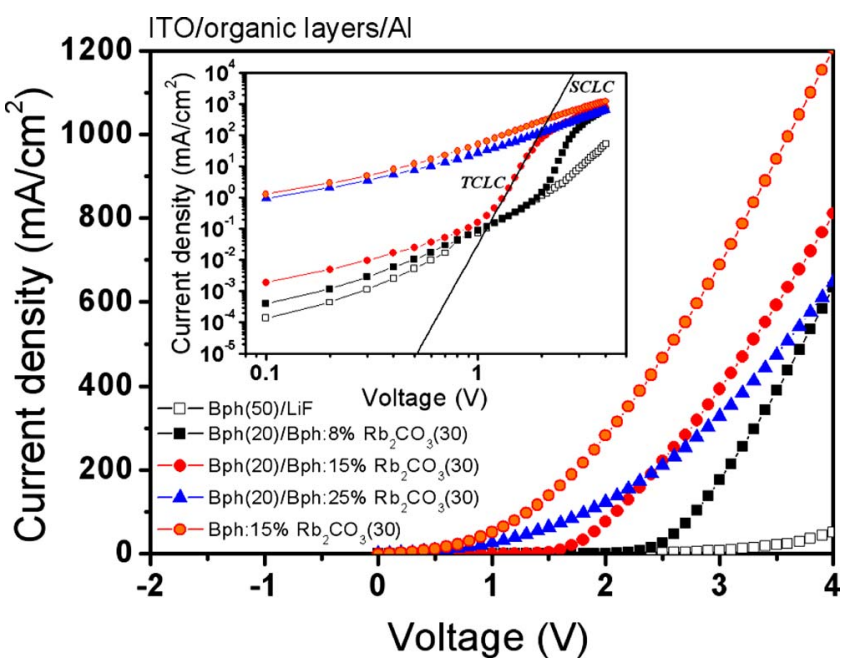

Figure 1. (Color online) $J-V$ characteristics of electron-only devices with ITO/Bphen $(20 \mathrm{~nm}) / \mathrm{Bphen}: 8-25 \% \mathrm{Rb}_{2} \mathrm{CO}_{3}(30 \mathrm{~nm}) / \mathrm{Al}$ and conventional ITO/Bphen $(50 \mathrm{~nm}) / \mathrm{LiF} / \mathrm{Al}$ structures. (Inset) $\mathrm{Log}-\log$ plots of the $J$ - $V$ characteristics of the devices. 


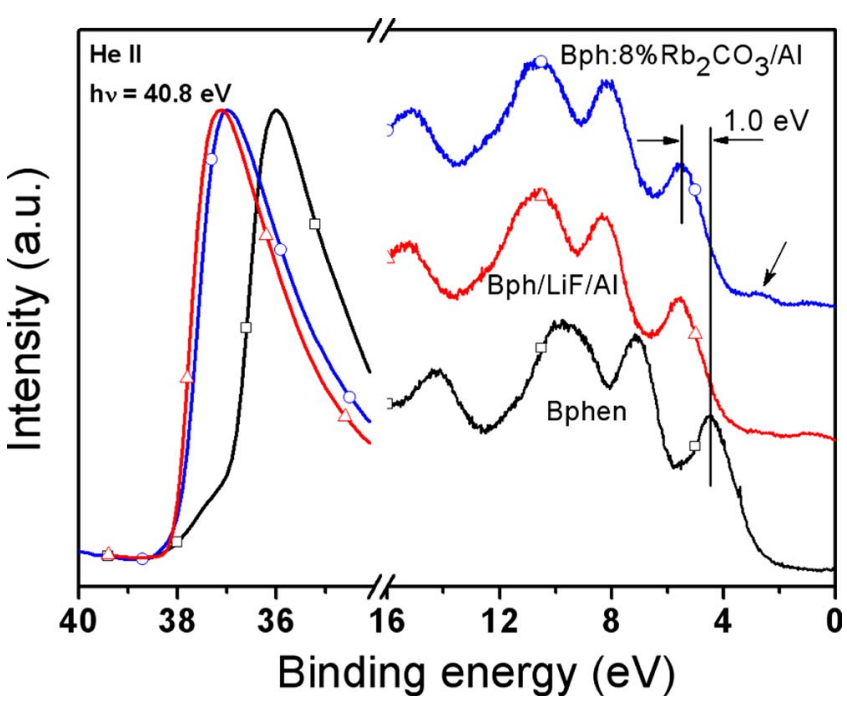

Figure 2. (Color online) UPS spectra near the onset and valence bands of the pristine Bphen, Bphen $(29 \AA) / \mathrm{Bphen}: 8 \% \mathrm{Rb}_{2} \mathrm{CO}_{3}(14 \AA) / \mathrm{Al}(3 \AA)$, and Bphen $(40 \AA) / \mathrm{LiF}(2 \AA) / \mathrm{Al}(5 \AA)$ samples.

density at the same voltage compared to that with a Bphen/ Bphen: $8 \% \quad \mathrm{Rb}_{2} \mathrm{CO}_{3}$ layer. The device with a Bphen/Bphen:25\% $\mathrm{Rb}_{2} \mathrm{CO}_{3}$ layer shows a low threshold voltage, but the current density is found to decrease at high driving voltages. The inset of Fig. 1 displays $\log -\log$ plots of the $J-V$ characteristics of the devices. The $J-V$ curves of the devices with Bphen/Bphen:8-15\% $\mathrm{Rb}_{2} \mathrm{CO}_{3}$ layers exhibit three distinct regions: an Ohmiclike current $(J \propto V)$ region at low voltages, followed by a trap-charge limited-current (TCLC) $\left(J \propto V^{n}, n>10\right)$ region at intermediate voltages and a space-charge limited-current $\left(J \propto V^{2}\right)$ region at high bias voltages. ${ }^{17}$ The electron-only device of the ITO/Bphen: $15 \% \mathrm{Rb}_{2} \mathrm{CO}_{3} / \mathrm{Al}$ structure without an undoped Bphen layer exhibits no TCLC region in the $J$ - $V$ characteristics, and its electrical conductivity was calculated to be $5.0 \times 10^{-6} \mathrm{~S} / \mathrm{cm}$. The device with a Bphen/Bphen: $25 \% \mathrm{Rb}_{2} \mathrm{CO}_{3}$ layer also shows no TCLC region in spite of the existence of undoped Bphen layer. This fact suggests that heavy doping may cause a significant diffusion of the dopant into the undoped Bphen layer, indicating that the dopant can diffuse into an EML of real OLEDs to degrade the device efficiency and stability if the doped layer is in contact with an EML. ${ }^{6,18}$ Based on the $J$ - $V$ characteristics, we selected $15 \%$ doping ratio of $\mathrm{Rb}_{2} \mathrm{CO}_{3}$ in the Bphen layer as the optimum condition of n-ETL. The $J-V$ characteristics can be further controlled by the adjustment of thicknesses of the doped and undoped Bphen layer.

To investigate possible charge-injection and -transport mechanisms of the $\mathrm{Rb}_{2} \mathrm{CO}_{3}$-doped Bphen ETL system, UPS analysis was carried out. Figure 2 shows the UPS spectra near the onset and the valance bands of the pristine Bphen, Bphen/Bphen: $8 \% \mathrm{Rb}_{2} \mathrm{CO}_{3} / \mathrm{Al}$, and $\mathrm{Bphen} / \mathrm{LiF} / \mathrm{Al}$ samples. The UPS analysis of the Bphen:8\% $\mathrm{Rb}_{2} \mathrm{CO}_{3} / \mathrm{Al}$ structure clearly shows that the onset and the valanceband spectra largely shift toward the higher-binding-energy side by $1.0 \mathrm{eV}$ compared to that of the pristine Bphen layer. This suggests that the doping of $\mathrm{Rb}_{2} \mathrm{CO}_{3}$ in Bphen induces the movement of Fermi level toward the lowest unoccupied molecular orbital (LUMO) and consequently reduces the electron-injection barrier. ${ }^{14}$ In addition to that, extra states are formed in the forbidden gap as indicated by the arrow for the Bphen:8\% $\mathrm{Rb}_{2} \mathrm{CO}_{3} / \mathrm{Al}$ system, facilitating the effective charge-carrier injection and transport. ${ }^{14,15}$ The Bphen/LiF/Al reference also exhibits the large shift of onset and valence-band spectra toward the higher binding energy, but no evidence of the formation of gap states is found for the structure. These results indicate that the reduction of the barrier height for electron injection

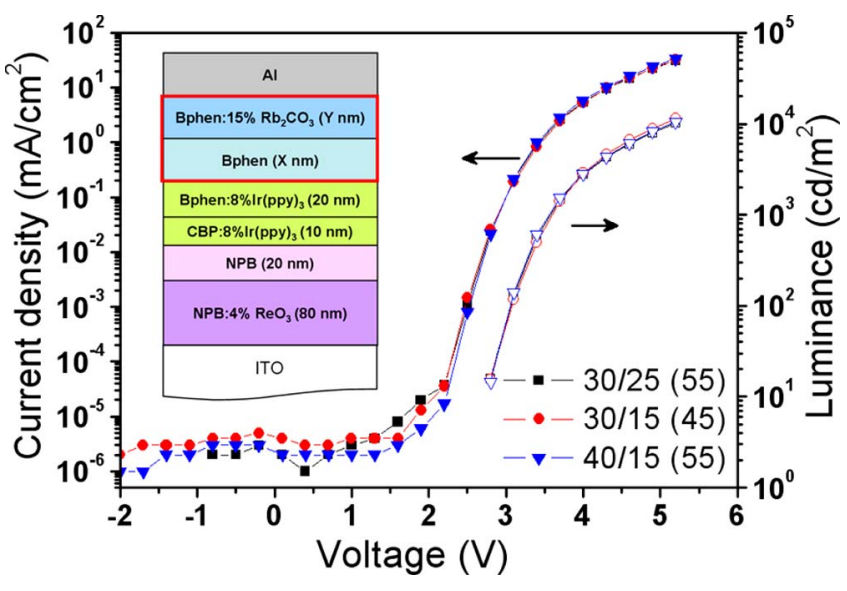

Figure 3. (Color online) $J-V-L$ characteristics of p-i-n OLEDs with ITO/ $\mathrm{NPB}: 4 \% \quad \mathrm{ReO}_{3} \quad(80 \mathrm{~nm}) / \mathrm{NPB} \quad(20 \mathrm{~nm}) / \mathrm{D}-\mathrm{EML} \quad(30 \mathrm{~nm}) /$ Bphen $\quad(X$ $\mathrm{nm}) / \mathrm{Bphen}: 15 \% \mathrm{Rb}_{2} \mathrm{CO}_{3}(Y \mathrm{~nm}) / \mathrm{Al}$ with different thicknesses of Bphen and Bphen: $15 \% \mathrm{Rb}_{2} \mathrm{CO}_{3}$ layers. (Inset) Schematic illustration of the device structure.

and the creation of gap states in the Bphen: $\mathrm{Rb}_{2} \mathrm{CO}_{3} / \mathrm{Al}$ system contribute to the enhancement of electron-injection and -transport characteristics of the $\mathrm{Rb}_{2} \mathrm{CO}_{3}$-doped Bphen system.

Based on the above results, we fabricated the p-i-n OLEDs using the Bphen: $\mathrm{Rb}_{2} \mathrm{CO}_{3}$ ETL system. In order to investigate the chargetransporting ability of the n-ETL, devices with different thicknesses of undoped ETL and n-ETL were made and characterized, where $4 \%$ $\mathrm{ReO}_{3}$-doped NPB was used as p-HTL. The schematic diagram of the device structure is shown in the inset of Fig. 3. Four percent $\mathrm{ReO}_{3}$ doping in HTL was preferentially examined and selected as the optimum $\mathrm{p}$-doping condition to fabricate the $\mathrm{p}$-i-n OLEDs under the fixed ETL/n-ETL thicknesses $(30 / 25 \mathrm{~nm})$. A higher $(8 \%)$ or lower (2\%) p-doping concentration resulted in the relatively inferior device performance (not shown).

Figure 3 exhibits the $J-V-L$ characteristics of OLEDs with different ETL geometries. All the devices show almost the same electrical properties (driving voltages of $3.1 \mathrm{~V}$ at $100 \mathrm{~cd} / \mathrm{m}^{2}$ and $3.6 \mathrm{~V}$ at $1000 \mathrm{~cd} / \mathrm{m}^{2}$ ), irrespective of the change of ETL/n-ETL thicknesses. The variation in efficiencies of $\mathrm{p}$-i-n OLEDs with the change of ETL/n-ETL thicknesses is shown in Fig. 4. The device with

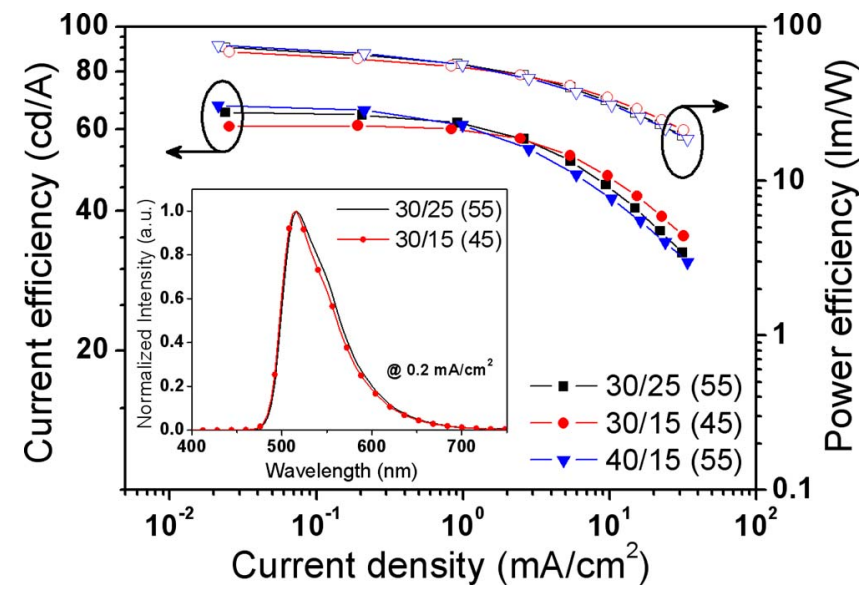

Figure 4. (Color online) $J-V$ characteristics of p-i-n OLEDs with ITO/ NPB:4\% $\mathrm{ReO}_{3}(80 \mathrm{~nm}) / \mathrm{NPB}(20 \mathrm{~nm}) / \mathrm{D}-\mathrm{EML}(30 \mathrm{~nm}) /$ Bphen $(X \mathrm{~nm}) /$ Bphen:15\% $\mathrm{Rb}_{2} \mathrm{CO}_{3}(Y \mathrm{~nm}) / \mathrm{Al}$ with different thicknesses of Bphen and Bphen: $15 \% \quad \mathrm{Rb}_{2} \mathrm{CO}_{3}$ layers. (Inset) Electroluminescence spectra of the devices. 


\begin{tabular}{|c|c|c|c|c|c|c|}
\hline \multirow{2}{*}{$\begin{array}{l}\text { ETL/n-ETL } \\
(\mathrm{nm})\end{array}$} & \multicolumn{3}{|c|}{$\eta_{\mathrm{L}}\left(\mathrm{cd} \mathrm{A}^{-1}\right)$} & \multicolumn{3}{|c|}{$\eta_{p}\left(\operatorname{lm~W^{-1})}\right.$} \\
\hline & Peak & $1 \mathrm{~mA} / \mathrm{cm}^{2}$ & $10 \mathrm{~mA} / \mathrm{cm}^{2}$ & Peak & $1 \mathrm{~mA} / \mathrm{cm}^{2}$ & $10 \mathrm{~mA} / \mathrm{cm}^{2}$ \\
\hline $30 / 25$ & 65 [18.5\%] & 62 & 45 & 73 & 57 & 33 \\
\hline $30 / 15$ & $61[17.6 \%]$ & 60 & 47 & 68 & 55 & 34 \\
\hline $40 / 15$ & $68[19.2 \%]$ & 62 & 43 & 76 & 56 & 31 \\
\hline
\end{tabular}

$30 \mathrm{~nm}$ thick ETL and $25 \mathrm{~nm}$ thick n-ETL produces maximum current efficiency of $65 \mathrm{~cd} / \mathrm{A}$ and power efficiency of $73 \mathrm{~lm} / \mathrm{W}$. Furthermore, the efficiencies are slightly improved for the device with ETL/n-ETL thicknesses of $40 / 15 \mathrm{~nm}$, which features a maximum current efficiency of $68 \mathrm{~cd} / \mathrm{A}$ and a power efficiency of $76 \mathrm{~lm} / \mathrm{W}$. The corresponding EQE of the device is $19.2 \%$. Additional variation of ETL/n-ETL thicknesses to $30 / 15 \mathrm{~nm}$ results in the reduction of device efficiency. Further details of the device performances are summarized in Table I. The whole p-i-n OLEDs with the developed ETL/n-ETL systems show high device efficiencies (max. $61-68 \mathrm{~cd} / \mathrm{A}$ and $68-76 \mathrm{~lm} / \mathrm{W}$ ) and equivalent operation voltages of $3.6 \mathrm{~V}$ at $1000 \mathrm{~cd} / \mathrm{m}^{2}$ regardless of the ETL/n-ETL thickness. These results suggest that the developed Bphen: $\mathrm{Rb}_{2} \mathrm{CO}_{3}$ doping system possesses stable electron-transporting ability to provide electrically well-balanced charge-carrier movement within the OLEDs. The small change in device efficiency may be associated with optical characteristics such as the wide-angle interference effect. ${ }^{19,20}$ Indeed, the electroluminescence spectra of the OLEDs are slightly different with the change of ETL/n-ETL thickness, as shown in the inset of Fig. 4.

In summary, the electrical properties and possible carriertransport mechanisms of the $\mathrm{Rb}_{2} \mathrm{CO}_{3}$-doped Bphen n-ETL system have been investigated. Superior charge-injection and -transporting characteristics were obtained from the Bphen: $\mathrm{Rb}_{2} \mathrm{CO}_{3}$ doping system, which is mainly attributed to doping-induced Fermi level shift toward the LUMO level of Bphen and the formation of gap states. Green phosphorescent p-i-n OLEDs with various ETL/n-ETL thicknesses exhibited high current efficiencies of $\sim 68 \mathrm{~cd} / \mathrm{A}$, power efficiencies of $\sim 76 \mathrm{~lm} / \mathrm{W}$, and low operation voltages of $3.6 \mathrm{~V}$ at $1000 \mathrm{~cd} / \mathrm{m}^{2}$. These results indicate that the Bphen: $\mathrm{Rb}_{2} \mathrm{CO}_{3}$ doping system possesses a stable charge-transporting ability and can play an important role as an efficient $\mathrm{n}$-doping system for high-performance p-i-n OLEDs.

\section{Acknowledgments}

The authors thank the MKE of Korea and Samsung SDI for their financial support of this work.
Seoul National University assisted in meeting the publication costs of this article.

\section{References}

1. Y. Sun, N. C. Giebink, H. Kanno, B. Ma, M. E. Thompson, and S. R. Forrest, Nature (London), 440, 908 (2006).

2. C. Adachi, M. A. Baldo, M. E. Thompson, and S. R. Forrest, J. Appl. Phys., 90, 5048 (2001).

3. M. Ikai, S. Tokito, Y. Sakamoto, T. Suzuki, and Y. Taga, Appl. Phys. Lett., 79, 156 (2001).

4. D. Tanaka, H. Sasabe, Y.-J. Li, S.-J. Su, T. Takeda, and J. Kido, Jpn. J. Appl. Phys., Part 2, 46, L10 (2007).

5. G. He, M. Pfeiffer, K. Leo, M. Hofmann, J. Birnstock, R. Pudzich, and J. Salbeck, Appl. Phys. Lett., 85, 3911 (2004).

6. B. W. D'Andrade, S. R. Forrest, and A. B. Chwang, Appl. Phys. Lett., 83, 3858 (2003).

7. M. Pfeiffer, S. R. Forrest, K. Leo, and M. E. Thompson, Adv. Mater. (Weinheim, Ger.), 14, 1633 (2002).

8. K. Walzer, B. Maennig, M. Pfeiffer, and K. Leo, Chem. Rev. (Washington, D.C.), 107, 1233 (2007).

9. J. Endo, T. Matsumoto, and J. Kido, Jpn. J. Appl. Phys., Part 2, 41, L358 (2002).

10. C. Ganzorig and M. Fujihira, Appl. Phys. Lett., 77, 4211 (2000).

11. C.-C. Chang, M.-T. Hsieh, J.-F. Chen, S.-W. Hwang, and C. H. Chen, Appl. Phys. Lett., 89, 253504 (2006).

12. H. Ikeda, J. Sakata, M. Hayakawa, T. Aoyama, T. Kawakami, K. Kamata, Y. Iwaki, S. Seo, Y. Noda, R. Nomura, et al., SID Int. Symp. Digest Tech. Papers, 37, 923 (2006).

13. D.-S. Leem, H.-D. Park, J.-W. Kang, J.-H. Lee, J. W. Kim, and J.-J. Kim, Appl. Phys. Lett., 91, 011113 (2007).

14. C.-I. Wu, C.-T. Lin, Y.-H. Chen, M.-H. Chen, Y.-J. Lu, and C.-C. Wu, Appl. Phys. Lett., 88, 152104 (2006).

15. S.-Y. Chen, T.-Y. Chu, J.-F. Chen, C.-Y. Su, and C. H. Chen, Appl. Phys. Lett., 89, 053518 (2006)

16. J. Huang, Z. Xu, and Y. Yang, Adv. Funct. Mater., 17, 1966 (2007).

17. G. He, O. Schneider, D. Qin, X. Zhou, M. Pfeiffer, and K. Leo, J. Appl. Phys., 95, 5773 (2004).

18. S. Watanabe, N. Ide, and J. Kido, Jpn. J. Appl. Phys., Part 1, 46, 1186 (2007).

19. S. K. So, W. K. Choi, L. M. Leung, and K. Neyts, Appl. Phys. Lett., 74, 1939 (1999).

20. C.-L. Lin, T.-Y. Cho, C.-H. Chang, and C-. C. Wu, Appl. Phys. Lett., 88, 081114 (2006). 